\title{
Book review: A. Fowler and F. Ng (Eds.), 2020. Glaciers and Ice Sheets in the Climate System: The Karthaus Summer School Lecture Notes.
}

\section{Communication}

Cite this article: Hock R, Truffer M (2022). Book review: A. Fowler and F. Ng (Eds.), 2020. Glaciers and Ice Sheets in the Climate System: The Karthaus Summer School Lecture Notes. Journal of Glaciology 68(270), 829-830. https:// doi.org/10.1017/jog.2021.129

First published online: 13 December 2021

\section{Springer Textbooks in Earth Sciences, Geography and Environment ISSN: 2510-1307 (2510-1315 ebook), doi: 10.1007/978-3-030-42584-5; ebook €71.7, hardcover $€ 88.4$}

\author{
Regine Hock ${ }^{1,2}$ (D) and Martin Truffer 2,3 (iD)
}

${ }^{1}$ Department of Geosciences, University of Oslo, Oslo, Norway; ${ }^{2}$ Geophysical Institute, University of Alaska
Fairbanks, Fairbanks, USA and ${ }^{3}$ Department of Physics, University of Alaska Fairbanks, Fairbanks, USA

Almost every year in the past quarter-century, a cohort of about 35 glaciology students and several instructors from all over the world descend upon the small village of Karthaus in the Italian Alps for the Karthaus Summer School on Ice Sheets and Glaciers in the Climate System. The summer school was initiated by Johannes Oerlemans in 1995, and run ever since by the Institute for Marine and Atmospheric Research in Utrecht, The Netherlands. For many students, this 12-day intensive course has been transformative, and many have moved on to successful academic careers in glaciology. In fact, both reviewers are alumni of the very first summer school in 1995, which took place in Grindelwald, Switzerland.

Many of each year's roughly dozen instructors have been teaching at the summer school repeatedly, and handouts have been floating around and used far beyond each year's student cohort. Now, many of the high-quality lectures given in Karthaus are available in expanded form in a comprehensive book (Fowler and Ng, 2020) available in print and as an ebook, thus enhancing the Karthaus legacy even more.

The $>500$ pages book contains 20 chapters, each written by experts in the field who taught at the summer school, in total 34 authors from ten countries. Chapters span a wide range of glaciology-related topics most of which may broadly be categorized into (1) 'classical' physics of glaciers (such as ice dynamics, thermodynamics, mass balance and glacier hydrology), (2) observation and modeling techniques (including numerical/analytical modeling, remote sensing, geophysical methods), and (3) paleoglaciology (including ice cores, glacial landforms and glacier variations back to the early Cenozoic). Valuable additional chapters on polar meteorology, glacial isostatic adjustment, tropical glaciers, and GPS (as an example of least-square data inversion) broaden the scope of the book beyond what is typically covered in a glaciology textbook. An excellent final chapter on the history of glaciology in the Ötztal Alps provides not only context for the summer school's excursion, but also highlights interesting and perhaps less well-known historical aspects of the science of glaciology. In fact, many major scientific and methodological advances in glaciology have originated from $>100$ years of glacier research on benchmark glaciers in that area of the European Alps.

In general, the chapters provide excellent, crisp, well-written textbook-like overviews of each topic. The book is not a collection of research papers or comprehensive reviews, as different authorship for each chapter may suggest, but is envisioned as a textbook, targeting students from a wide range of disciplines. Consistent with the target audience, many chapters focus on fundamental concepts and methods rather than discussing the latest research, which will serve the book well with respect to longevity given that the field of glaciology has been rapidly evolving and growing in recent decades. Notably, many of the chapters are accompanied by great and thought-provoking exercises useful for promoting further understanding of the subject matter, and are also a great resource for instructors who may wish to incorporate them in their courses. The book is well illustrated with numerous figures depicting both research results and concepts. Unfortunately, a small but significant number of the figures and tables are printed in very small font, making them virtually illegible, which, in particular, is a problem for the hardcover version.

Editing a book with so many contributors is not an easy feat. The editors Andrew Fowler and Felix Ng are to be applauded for their remarkable job in homogenizing the material submitted by the individual authors, making the writing style and mathematical notation at least somewhat systematic and uniform. Nevertheless, as acknowledged by the editors, and typical of such a multi-author endeavor, a certain degree of inhomogeneity remains with respect to both content and style.

Naturally not all topics can be covered exhaustively in such a book, but some chapters succeed in doing so more than others. The degree to which technical details are presented or topics are dealt with in rigorous quantitative ways varies widely. Some chapters provide outstanding theoretical reports (e.g., Chapter 1 on slow viscous flow and Chapter 2 on 
thermodynamics), however, fall a bit short on providing 'real world' context. Thus, these chapters are less accessible to readers seeking broader (more descriptive) overviews. Some chapters (in particular Chapter 7 on mass balance, Chapter 13 on remote sensing, and Chapter 19 on tropical glaciers) are heavily biased toward featuring the authors' work and research tools, thus providing an incomplete report of the topic. If used as a class textbook these topics would need to be supplemented by additional material. Reference lists vary greatly, from 4 to 64 references per chapter, where some concentrate on giving key references to a few foundational works, whereas others seem to aim at being more comprehensive, although many of those show a great bias toward the authors' own work. Some chapters provide concluding remarks, while others end rather abruptly. The mass balance chapter uses terminology and notations somewhat inconsistent with the massbalance glossary by Cogley and others (2011), which is unfortunate given, in particular, the widespread and persistent confusion and inconsistency with respect to mass balance terminology in the literature.

Naturally, a book of this size and breadth in topic cannot be comprehensive. Hence, some topics are omitted or only touched on marginally in the book. For example, while there is an excellent comprehensive chapter on polar meteorology there is little on the meteorology and energy exchange of complex glacierized mountainous terrain. Also, little is said, for example, about polythermal glaciers, submarine melting at tidewater glaciers, surges, ice physics, firn processes in percolation zones, and some topics of high societal relevance, such as glacier hazards, marine ice sheet instabilities or future glacier changes. Generally, the book is somewhat focused on ice sheet glaciology, covering glacier environments and processes outside the ice sheets less comprehensively. Overall, such omissions and biases are not necessarily surprising given that the chapters are based on the Karthaus lectures, where what is taught also depends on the availability and willingness of academic instructors to volunteer their time. Naturally, some degree of (subjective) selectivity is also needed to keep the book at a manageable length. The ordering of the chapters may appear somewhat random in places, however, since each chapter is rather self-contained, this is not a big issue, and some of the more foundational chapters do appear first. Thanks to the admirable job done by the editors, the book is largely free of editorial issues, errors and inconsistencies.

The (minor) complaints above do not taint our overall impression of the book. The book is a highly valuable addition to the canon of existing books on glaciology. It provides concise and fairly comprehensive overviews of a wide range of topics in glaciology, some of which are not covered in any other textbook. It is at a level that can be recommended as a textbook for graduate or upper undergraduate level glaciology classes, especially if supplemented with suitable material from other textbooks or other sources on the topics covered less comprehensively or only marginally. Most chapters are also well-suited for any science-literate person interested in glaciology with a basic understanding of the Earth's system. The book does not replace the experience of participating in summer school, but it will greatly expand the reach of these excellent lectures to a much broader community of students, instructors, and researchers.

\section{Reference}

Cogley JG and 10 others (2011) Glossary of Glacier Mass Balance and Related Terms. IHP-VII Technical Documents in Hydrology No. 86, IACS Contribution No. 2, UNESCO-IHP, Paris. 114 pp.

Fowler A, Ng F (eds) (2020) Glaciers and Ice Sheets in the Climate System: The Karthaus Summer School Lecture Notes. Springer Textbooks in Earth Sciences, Geography and Environment, https://doi.org/10.1007/978-3-03042584-5 